\title{
IYD
}

http://jyd. pitt. edu/ | Vol. 13 Issue 3 DOI 10.5195/jyd.2018.604 | ISSN 2325-4017 (online)

\section{Disability Inclusion in 4-H: Aligned with the Mission, Stopped Short by Methods}

\author{
Jennifer J. Taylor-Winney \\ Western Oregon University \\ taylorj@mail.wou.edu \\ Leanne S. Giordono \\ Oregon State University \\ giordon/@oregonstate.edu \\ Marilyn K. Lesmeister \\ Oregon State University \\ marilyn.lesmeister@oregonstate.edu \\ Meghann L. Fenn \\ Oregon State University \\ fennm@oregonstate.edu

\section{Gloria Krahn} \\ Oregon State University \\ gloria.krahn@oregonstate.edu
}

\begin{abstract}
Quality out-of-school programs can significantly improve youth development outcomes. Youth with disabilities and special health care needs, who represent $19 \%$ of all youth, are less likely than their typically developing peers to participate in out-of-school activities. This qualitative study explored factors that influence the inclusion of youth with disabilities in one state's 4-H program. Factors that facilitated inclusion were personal attitudes and subjective norms, but lack of knowledge and limited resources led to reactive problem solving rather than proactive, organizational planning. By identifying both the factors that facilitate inclusion and those that prevent it or are perceived as barriers, youth development professionals can target areas of focus to improve inclusion of youth with disabilities in 4-H and potentially other youth development programs.
\end{abstract}

Key words: disability inclusion, 4-H, out-of-school, theory of planned behavior, staff

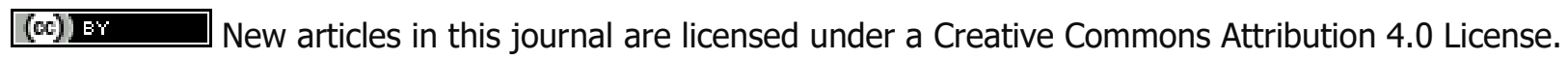
This journal is published by the University Library System, University of Pittsburgh and is cosponsored by the University of Pittsburgh Press. The Journal of Youth Development is the official peer-reviewed publication of the National Association of Extension 4-H Agents and the National AfterSchool Association. 


\section{Introduction}

Research over the past decades has demonstrated benefits to youth who participate in quality out-of-school programs (including after-school programs). These benefits include academic gains, social-emotional competence, health, peer acceptance, physical activity, and character development (Apsler, 2009; Durlak, Weissberg, \& Pachan, 2010; Trost, Rosenkranz, \& Dzewaltowski, 2008; Watts, Witt, \& King, 2008). Program staff are known to play a key role in the effectiveness of after-school programs and outcomes of participating youth (Apsler, 2009; Daud \& Carruthers, 2008; Riggs \& Greenberg, 2004). Greater attention is now being directed to the conceptual and methodological approaches for studying youth development programs (e.g., Arnold \& Silliman, 2017), with a call for greater application of research findings to program practice (Deutsch, Blyth, Kelly, Tolan, \& Lerner, 2017). In particular, youth with disabilities are a population requiring more attention. The Americans with Disabilities Act (1990) defines a person with a disability as a person who has a physical or mental impairment that substantially limits one or more major life activity, someone who has a record of such an impairment, or is regarded as having a disability.

For youth with disabilities inclusion in out-of-school programs provides important socialization experiences with peers, as well as acquisition of content knowledge and skills. Youth with disabilities are known to benefit from and enjoy participation in formal after-school activities (Fennick \& Royal, 2003; King, Petrenchiky, Law, \& Hurley, 2009). Successful inclusion can foster a sense of community and connection for youth with disabilities. For in-school programs, where more research on outcomes is available, inclusive education is associated with greater enrollment in postsecondary education (Rojewski, Lee, \& Gregg, 2015). For youth without disabilities, disability inclusion can provide a deeper understanding and appreciation of human diversity. Failure to include youth with disabilities explicitly can be experienced as exclusion and discrimination (Lindsay \& McPherson, 2011), and may reinforce a sense of difference or "othering" by their able-bodied peers.

Despite these benefits, youth with disabilities and special health care needs participate in afterschool programs at lower rates than youth generally. About $19 \%$ of all youth are identified as having disabilities or special health care needs, but they are much less likely to participate in out-of-school activities than typically developing peers, as indicated by parent report (National Survey of Children's Health, 2016) and by teacher report (Kleinert, Miracle, \& Sheppard-Jones, 2007). The lack of inclusion of youth with disabilities has been attributed to staff attitudes about inclusion, lack of accommodations by organizations, barriers in the physical environment, 


\section{Disability Inclusion in 4-H}

stereotypical labeling, and negative attitudes about individuals with disabilities by staff (Foley, Bryan, \& McCubbin, 2008; Rimmer, Rowland \& Yamaki, 2007; Taylor \& Yun, 2012).

The national 4-H Youth Development Program (4-H) is an out-of-school program for youth ages 6 to 19 years that reaches nearly 6 million youth annually in the United States in urban (1.8 million), suburban (1.6 million) and rural (2.6 million) communities (National 4-H Council, 2016). Legislated by the U.S. Congress, the 1914 Smith-Lever Act created 4-H as part of Cooperative Extension programs of every land-grant university. Professionals and volunteers work together to conduct 4-H programs in nearly every county in the United States. The intent of 4- $\mathrm{H}$ is to serve as a university-connected program for the practice of youth development through experiential learning experiences, positive relationships between youth and adults, safe environments, and opportunities for positive risk taking. The National Institute of Food and Agriculture (NIFA) within the U.S. Department of Agriculture (USDA) provides federal funding to land-grant universities for 4-H educational programming. State and county governments provide additional program funding that is augmented through private and corporate donations, as well as state $4-\mathrm{H}$ foundations and National $4-\mathrm{H}$ Council. While these national organizations provide guidance, each state has a high degree of autonomy with respect to management and implementation of programming.

While county 4-H programs collect demographic data on participants based on national and state guidelines, information on disability status is not systematically collected. Disability inclusion has received little attention in 4-H literature, with a recent review of the Journal of Extension identifying only 16 articles relating to disability inclusion in 4-H since 1990 (TaylorWinney, Xue, McNab, \& Krahn, 2017). Of these, ten studies relate to specific strategies for accommodation, six address attitudes and needs of extension agents toward inclusion, one addresses training practices for 4-H camps, and one describes a multi-year project to develop and implement an inclusion curriculum.

The current study sought to understand staff perspectives on the status of disability inclusion in 4- $\mathrm{H}$, what barriers to inclusion are perceived to exist, and what facilitates inclusion of youth with disabilities and other special health needs. The relative paucity of information on disability inclusion in 4-H led us to select a qualitative method for exploring staff perspectives. To frame the study, a theory-informed approach was used to disentangle the determinants of 4-H staff inclusive behavior (e.g., staff attitudes, program accommodations). 


\section{Method}

This study takes an evaluative approach that situates qualitative research activities in a theory of change (Weiss, 1998), treating disability inclusion as a positive outcome that has been articulated by 4-H as a goal. Specifically, we posit that 4-H staff and leadership behaviors influence the level and quality of disability inclusion. As such, we selected a theory that focuses on individual behavior change.

\section{Theory}

The study used the theory of planned behavior (TPB) (Ajzen, 1991) as its theoretical foundation. Within this framework of individual behavior change, behavioral beliefs, normative beliefs, and control beliefs represent the observable outcomes that comprise the constructs of attitude, subjective norms, and perceived behavioral control (see Figure 1). TPB posits that there is a relationship among attitude, subjective norms, perceived behavioral control, and intent to perform a behavior, and that intent is related to actual performance of the behavior. This differentiation among constructs can potentially identify where difficulties with disability inclusion arise.

Figure 1. Theory of Planned Behavior Model (Ajzen, 1991)

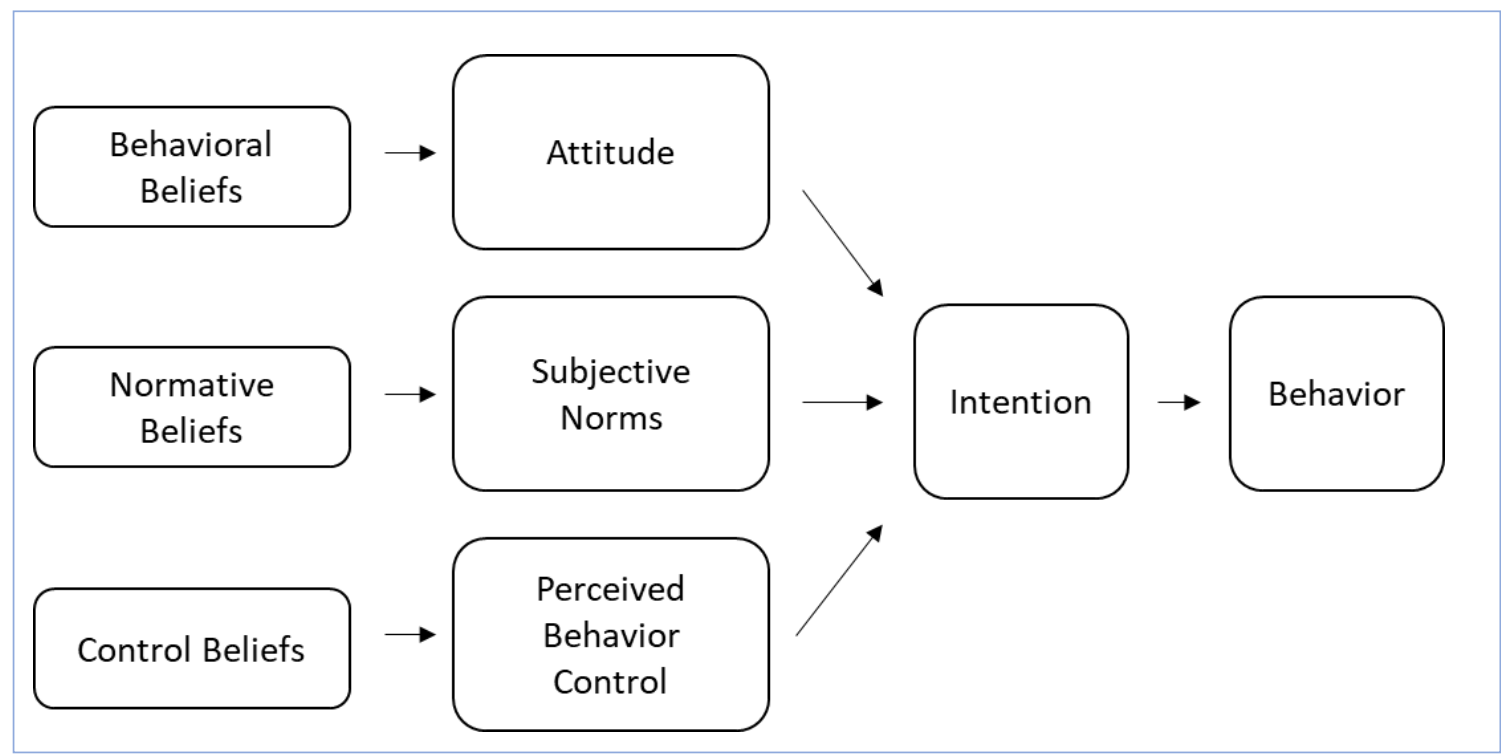




\section{Protocol Development}

We developed a theory-informed, semi-structured interview protocol designed to elicit respondents' perceptions and experiences related to inclusion of youth with disability in 4-H programming. The protocol included up to 16 questions and related prompts that correspond to TPB constructs, respondent role and background, with slight adaptations made for each staff group. The protocol included a verbal statement of informed consent that was read to all respondents prior to the interview, and all respondents were assured confidentiality to promote candid responses. Interviewees were informed that "disability" referred to "all disabilities and may include but are not limited to developmental disabilities such as Down syndrome and autism; physical disabilities such as spinal cord injury, spina bifida, or cerebral palsy; learning disabilities; or behavioral disabilities." Two members of the research team, who are also 4-H staff members, played an integral role during protocol development to ensure the relevance of protocol questions in the 4-H context.

\section{Respondent Selection}

We conducted purposeful selection (Light, 1990; Maxwell, 2013; Weiss, 1994) of a sample of 24 study respondents from among county, state, and national 4-H staff. All county and state staff were selected from one western state considered typical of 4-H youth programs based on the widespread presence of county-based programming, including 4-H clubs and other short-term participation opportunities. National leaders were selected to provide their perspective on national programmatic trends, initiatives, and guidance. County staff were selected from five geographic areas (one or two counties each) to represent variation in (a) state geographic and demographic diversity, (b) staff characteristics, and (c) 4-H programming diversity. State administrators were selected to represent geographic diversity, gender, professional years of experience, and role (e.g., campus administrator or off-campus manager). National leaders were selected for their role in administrative or committee positions. All individuals selected for the sample agreed to participate in an interview. See Table 1 for a summary of the sample by staff group, gender and administrative experience. 
Disability Inclusion in 4-H

Table 1. Interview Participants by Role, Gender, and Years of Experience in 4-H.

\begin{tabular}{|l|c|c|c|c|}
\hline & \multicolumn{2}{|c|}{ Gender } & \multicolumn{2}{c|}{$\begin{array}{c}\text { Professional experience } \\
\text { Staff group }\end{array}$} \\
\hline County $(n=10)$ & $50 \%$ & Female & $<10$ years & $\geq 10$ years \\
\hline State $(n=10)$ & $60 \%$ & $50 \%$ & $50 \%$ & $50 \%$ \\
\hline National $(n=4)$ & $25 \%$ & $70 \%$ & $30 \%$ & $70 \%$ \\
\hline Total & $50 \%$ & $50 \%$ & $50 \%$ & $50 \%$ \\
\hline
\end{tabular}

\section{Data Collection}

Members of the research team conducted interviews between December 2015 and June 2017. Using the semi-structured interview protocol as a guide, in-person interviews were conducted with county staff and state administrators $(n=20)$ and telephone interviews with national leadership $(n=4)$. A second researcher was present at all in-person interviews serving as a note taker. Twenty-one interviews were audio-recorded with respondent permission. Recording equipment failure required that for three interviews the interviewer notes were used as the primary data source. Interviews lasted an average of 35 minutes, were transcribed for subsequent analysis, and were checked against interviewer notes.

\section{Analysis}

The study used a thematic analysis approach (Braun \& Clarke, 2006) involving a multi-step, iterative process with multiple indicators of trustworthiness. This approach included prolonged engagement with the data, peer debriefing and use of a coding framework, detailed notes and hierarchies, vetting across the six team members, and detailed records about the coding and analysis process (Nowell, Norris, White, \& Moules, 2017). First, researcher pairs independently reviewed transcripts and conducted manual theme-based coding by TPB construct (attitude, subjective norm, perceived behavioral control, intention, and behavior). Each researcher then prepared a respondent-specific analytic memo that organized the data, related quotations, and analytic notes by TPB construct. Each researcher pair then reviewed and edited their respective respondent memos until agreement was achieved. To ensure consistent application of the analytic process, researchers were assigned to different (rotating) researcher pairs across transcripts. Second, the data and analytic notes from all respondent memos were entered into an Excel spreadsheet by TPB construct and analyzed for within-construct commonalities and variations, as well as emerging subthemes across all respondents and by staff groups. Finally, 
Disability Inclusion in 4-H

researchers prepared analytic memos for each TPB construct that highlighted key analytic observations for inclusion in study findings. During the entire analytic process, all members of the research team reviewed all memos and participated in regular analytic meetings to discuss results. The two 4-H staff members on the research team provided critical input and feedback about context-based interpretation of the data based on organizational culture and group roles.

\section{Results}

We organized the results around the five conceptual constructs related to the Theory of Planned Behavior. Subthemes that emerged from the data are also presented, with a focus on both facilitators and barriers to inclusion.

\section{Attitude}

Attitude describes an individual's beliefs related to the likely consequences of inclusion (i.e., behavioral beliefs). Respondent's attitudes toward disability inclusion were almost uniformly positive, although perceptions about the meaning of "inclusion" varied substantially. A few respondents expressed positive attitudes but also expressed reservations about inclusion.

\section{Positive Attitudes}

Respondents widely believed that there are benefits to disability inclusion for all 4-H stakeholders, as well as for the broader community. Some respondents specifically stated that creating an inclusive environment would provide an opportunity for youth with disabilities to gain the benefits that come with participation in 4-H.

The community is made up of many people with many perspectives, and whenever we can do something that raises the self-esteem and the feeling of worth of an individual-no matter their ability - within a community, it has a positive impact on that community (National Staff).

\section{Conceptual Variation}

Among some respondents, inclusion means actively differentiating among participants to address the needs of each child. For other respondents, inclusion broadly means treating all youth the same and discounting difference. 
Disability Inclusion in 4-H

I think all youth have their own form of disability, I mean

everybody does . . . whatever your personal story is. It might not

be defined as a physical disability, but it's your story, and so I

think everyone's walking their own path (State Staff).

\section{Selected Reservations}

Some respondents expressed reservations related to availability of resources (e.g., time, cost of accommodations) and the potential to draw resources away from other youth. One state staff member noted, "I guess, if you're assuming we have the same limited resources that we have now, that would be fewer programs for the others." Others anticipated concerns regarding fairness in competitive 4-H events-if accommodations were made for youth with disabilities, would that give them an unfair advantage in competitions?

Most of the frustration, comments, complaints, or phone calls that I get are from parents of kids [who don't have] disabilities . . It's after we've made an accommodation, that [there is a] feeling that we're being unfair to . . . their son or daughter (State Staff).

\section{Subjective Norms}

Subjective norms relate to the normative expectations of others (i.e., normative beliefs). Most respondents described inclusion as a 4-H organizational norm, and described motivations that include alignment with the 4-H mission, personal commitment, and an interest in the equitable representation of underserved populations. Respondents rarely cited civil rights and legal responsibilities under the Americans with Disabilities Act as part of the subjective norms for inclusion.

\section{Alignment with 4-H Mission}

Respondents widely described inclusion as being fully aligned with the 4- $\mathrm{H}$ mission, illustrated in this comment by a county staff member, "Well I think it goes back to the core of 4-H, that, 4-H is for everybody." 


\section{Varied Motivations for Inclusion}

Some respondents framed their own motivation in relation to the 4- $\mathrm{H}$ mission, while others expressed their beliefs in personal terms, describing inclusion as the right thing to do. Several respondents also described a commitment to underserved populations.

I believe we reach a youth population who would, without us, be pretty successful. They're forward thinking, they've got parent support, . . . dedication, drive, and goals. And that shows through their 4-H work. The . . youth in the $K-12$ group [that] we don't reach may not have all those attributes. [So] . . equitable availability. . . is something that I think about (State Staff).

A county staff member remarked, "These children are all our community's children, so we expect to include them."

\section{Perceived Control}

Perceived behavioral control relates to beliefs about factors that may help or hinder performance of the behavior (control beliefs). Perceived control is inclusive of resources, authority, knowledge, and skills. Most respondents described a deficit of and lack of familiarity with relevant resources, and many noted that data that 4-H collects on youth with disabilities are incomplete. Perceived authority varied by level of work responsibility. Knowledge and skills tended to vary by experience.

\section{Inadequate and/or Unknown Resources}

Many respondents, especially county staff, pointed to both a resource deficit and unfamiliarity with resources related to disability accommodations, curricula, technical support, and/or financial support. County staff typically named one specific state staff member as their primary resource.

[The university may] . . have a big push on diversity, inclusion . .

. but [the university] doesn't provide [financial] support. . . . They provide information [and] maybe training. [When] it becomes a core value . . . there should be financial backing to make it happen (County Staff). 


\section{Inadequate Data}

Respondents frequently described a lack of understanding about the number of actual youth participants or prospective community youth participants with disabilities. Some respondents connected the lack of data with their lack of motivation to be inclusive. One state staff participant stated, "I don't think we have a good handle on ... how many kids [with disabilities] we already are reaching . . . versus how many ... . [there are in communities.] [We need] some way of data tracking." A county interviewee expressed this uncertainty saying, "I walk into an existing [4-H] program and there might be some members with disabilities in the program and I may know about it, and I may not." Another county participant observed, "Many times we don't see the need until we look for it . . . but once I start trying to serve, I'll be surprised that it's a big number out there."

\section{Authority Varies by Work Responsibility}

Administrators expressed the strongest authority to influence inclusion broadly with some identifying that they are accountable to make sure inclusion happens. County staff described having control over their own programs, but little authority to influence 4-H more broadly, "The only thing I can control is whatever happens in my program." Notably, county staff expressed that they would not have authority to exclude youth with disabilities. State and national leadership acknowledged their responsibility to influence the broader organization. A state staff member said, "I have a lot of control over that [inclusion] and my role should be one to influence and change that." National leadership also acknowledged that each state has a high degree of autonomy to plan and implement their 4-H program and expressed having little direct control over inclusion in the field.

Control, hmm [laughs], that's a tough word. We can point them to civil rights laws and we can ... offer training opportunities, and point them to ... other resources that we've become aware of outside of NIFA (National Staff).

\section{Knowledge and Skills Vary by Experience}

Respondents with prior disability-related experience (either within 4-H or in their personal lives) tended to describe greater knowledge and skills about inclusive behaviors than those without prior experience.

I wouldn't necessarily call it easy, but . . . we have enough [volunteer] leaders and parents [who] have youth with disabilities 
Disability Inclusion in 4-H

in our program already that we have been able to accommodate most youth that have wanted that experience, in one way or another (County Staff).

How do I offer to help without insulting somebody? I don't want to alienate [the youth with a disability] . . I I haven't been in their shoes, so I don't know how to step up and help (State Staff).

\section{Intention}

Attitude, subjective norms, and perceived control are presumed to lead to the development of behavioral intention. Theoretically, the more positive one's attitude and subjective norms, and the greater their perceived control, the stronger their intention would be to include youth with disabilities. Intention is assumed to be a direct antecedent to behavior. Most respondents expressed continued willingness to be responsive, but across respondents there was little commitment to be proactive about future inclusion efforts. No respondent indicated intention to reduce inclusion efforts.

\section{Most Plan to Sustain Current Efforts}

Most staff responses, especially at the county level, expressed intent to maintain current inclusion efforts by remaining responsive to youth with disabilities. One county staff member claimed, "If I had a group of kids walk in from a deaf school right now saying we want to start [a club in 4-H] -I would definitely support them. I would have to figure out how."

\section{Few Proactive Change Strategies}

Only a few proactive and strategic steps were identified to improve inclusion. In the county role, staff generally were committed to continuing with their previous efforts; if they had been including youth with disabilities, they expressed intent to continue doing so. For others who had not actively engaged in including youth with disabilities, they provided little indication of intending to increase proactive approaches for disability inclusion, ". . . because it's more work, you know ... how am I supposed to get these 4 kids with autism into my club? It's just easier not to deal with it."

A quality I am going to look for in 4-H [volunteer] leaders and my staff is one that's able to ask those kinds of questions ..., but I 
Disability Inclusion in 4-H

think that is going to be a challenge because this is a volunteer organization (State Staff).

Well, we actually had the [National 4-H] vulnerable populations working group and champions chairs here, and we connected them with federal agencies that specialize in the particular area where they are champions, so we hope that those. . would help the system, hopefully open up more training opportunities, and perhaps, you know, some funding opportunities as well (National Staff).

\section{Behavior}

The behavior in question was the inclusion of youth with disabilities in 4-H programs. Many respondents described engaging in or contributing to inclusive behavior, but those accounts were anecdotal and reflected a problem-solving, rather than a strategic proactive approach to inclusion. Stories indicated mixed success, and respondents widely noted that disability inclusion outcomes in 4-H do not meet their expectations.

\section{Some Evidence of Inclusion}

Many respondents, especially at the county level, have directly engaged in or contributed to inclusion, but few respondents moved beyond anecdotes to describe more systemic approaches to inclusion.

One particular youth . . . operates at about a five-year-old level, and so when she [turned] twelve [we asked], 'how do we incorporate her [into] the program? Do we keep her [at the] . . . Cloverbud level?' And my answer was, "No, she needs to have the same experience as everyone else [her age]"(County Staff).

In animal science, in the show ring, there've been accommodations . . . finding a way to make it safe for them. . . . Get away from the actual project to what's important about youth development, and that's the leadership and the communication piece (County Staff). 


\section{Situational Problem-Solving Approach}

Respondents tended to describe inclusive behavior as a situational problem-solving approach, rather than being proactive and strategically planned. A state staff participant reported, "The way we handle programming [in rural areas], is... [that] kids with disabilities ... just come into the program. [We] just figure out how to do it without setting up special programs for them." A county staff interviewee described how their county addressed a situation:

We had a kid a couple of years ago who was in a wheelchair [and], had a steer . . . they were saying, 'How's the judge going to deal with this?' Well, we'll just talk to the judge and make it happen!

\section{Mixed Success}

Respondents described mixed results from inclusion efforts. While multiple respondents noted positive examples of inclusion, respondents highlighted ongoing disparities between participation by youth with and without disabilities in 4-H programming. Some administrators described challenging situations where parents requested more accommodations, while others described working with parents of youth with disabilities as an important resource.

We had . . . a boy with autism [at camp]. His mom came and she was super excited. She grew up in 4-H camps and she wanted him to have the same experience. . . . She struggled at times. She was crying because. . . she [was] constantly trying to coach us on how to work with him. . . . But she got frustrated because our volunteers and staff are not trained. They were trying to learn but it was hard. So they ended up having to go home early (County Staff).

You know, we have had kids with disabilities engaged, but more often than not they have been marginalized. . . . And it's one of really owning up to our moral responsibility . . . and figuring out ways that we can include them so that they can have a meaningful experience (National Staff). 


\section{Discussion}

The purpose of this study was to identify the current status of disability inclusion in 4- $\mathrm{H}$ in one western state. The study also sought to identify barriers and facilitators to inclusion that are experienced by this state's county and state staff as well as those experienced by national staff. While there have been calls for increased inclusion of youth with disabilities in 4-H (e.g., McBreen, 1994; Peterson et al., 2012), the status of disability inclusion within states' 4-H programs is largely undocumented. Multiple respondents in the present study cited the problem of lack of data about youth with disabilities, while providing anecdotes where they or others accommodated youth with diverse disabilities in 4-H programs.

Use of the framework and constructs of the theory of planned behavior informed a clearer delineation of where barriers to inclusion arise. The positive attitudes towards inclusion of youth with disabilities appear to facilitate inclusion, as do the subjective norms that the 4-H mission is to include all youth. These facilitators of inclusion align with findings of Taylor and Yun (2012) that program or organization expectations (subjective norms) had a positive influence on outof-school staff inclusion of youth with disabilities. Many respondents stated that disability inclusion is the "right thing to do" and is the mission of 4-H. This finding is consistent with previous research that reports generally positive attitudes toward disability inclusion in 4-H (e.g., Boone, Boone, Jr., Reed, Woloshuk, \& Gartin, 2006; Ingram, 1999; LaVergne, 2013). However, some respondents raised concerns about the reduction in resources to other programs, or the concern of "unfair advantage" that accommodations may give in competitions. The current findings are at some variance with previous research on other non-4-H programs where staff attitudes have been implicated as a barrier to inclusion (e.g., Anaby et al., 2013; Rimmer et al., 2007). This discrepancy may reflect the strong sense of mission that 4-H staff embody. Few respondents cited civil rights or protection from discrimination as a reason for disability inclusion.

Challenges to inclusion appear to center within the theoretical constructs of perceived behavior control and intention. Perceived behavioral control includes the themes of control, knowledge and skills, and resources for making behavioral change. Respondents in different roles reported control over different aspects of disability inclusion. County staff perceive having control only over including youth with disabilities in their specific programs, and shared their belief that state administrators have the control to promote inclusion through resource allocation, training, and data. State program administrators reported a sense of control over disability inclusion through budgetary allocations, but indicated the need for more compelling data and for more 


\section{Disability Inclusion in 4-H}

information on youth with disabilities and how to support their inclusion. National staff reported control in advocating for inclusion from a values and mission perspective, and in linking with national agencies, but not for mandates or budgetary decisions.

Intention for greater disability inclusion was not evident. It appears that this situation-where staff in all roles (county, state, and national) are positively inclined to include youth with disabilities based on personal and normative beliefs, but generally lack knowledge about disabilities, accommodations, and resources-has resulted in county staff adopting a reactive, problem-solving approach to inclusion. Such a strategy does not lead to expressed intention or strategies for proactively promoting participation of youth with disabilities and organizational planning for accommodation.

The barriers to inclusion in the present study appear to relate to a lack of data, to insufficient knowledge about disabilities and how to make accommodations among many staff in various roles, and to the perception that resources are limited or unknown. State and county respondents reported that the lack of time, money, and curricula contributed to the challenges of including youth with disabilities. A number of previous studies have identified the need for additional training of 4-H staff and volunteers on disability inclusion (e.g., Boone et al., 2006; Ingram, 1999; LaVergne, 2013; Peterson et al., 2012; Stumpf-Downing, Henderson, Luken, \& Bialeschki., 2004; Stumpf et al., 2002). Mouton and Bruce (2013) demonstrated that, compared with other American Camp Association camps, 4-H camps reported much less likelihood of indepth training (5 days or more), and less time on specific disability topics. On the other hand, individual 4-H programs have been developing a range of strategies for inclusion as summarized by Taylor-Winney et al. (2017).

National 4-H and the NIFA have recently launched a Vulnerable Populations initiative intended to increase the inclusion of several distinct, underserved groups, which includes youth with disabilities and youth with mental health needs (USDA, n.d.). The findings from the present study are intended to help inform this initiative, and other youth programs interested in greater inclusion of youth with disabilities. The use of a theoretical framework to identify facilitators and barriers is regarded as a unique contribution to the existing literature.

\section{Implications for Next Steps}

The current findings suggest several next steps for research and program activity. First, it is difficult to assess the status of disability inclusion without aggregate data on participation of 


\section{Disability Inclusion in 4-H}

youth with disabilities in 4-H. Better data are needed on the number and nature of youth with disabilities and whether or not they participate in 4-H. Respondents felt strongly that inclusion is a part of the mission of 4-H and can benefit all stakeholders. However, participants acknowledged that they were largely unaware of how many youth with disabilities were participating in 4-H. More accurate data on participation of youth with disabilities in 4-H could inform curriculum planning and implementation.

Second, the perceived availability of resources was identified as a barrier to inclusion. Respondents, especially county staff, identified the lack of training, curricula, and time as barriers to effective inclusion. A recent literature review (Taylor-Winney et al., 2017) identified some resources developed by $4-\mathrm{H}$ to foster inclusion of youth with disabilities and echoed the need for more resources. The current study underscores the need for staff to feel knowledgeable and better prepared to strategically facilitate disability inclusion.

Third, staff in all roles reported inclusion behaviors as a response to youth or families' requests. This reactive approach and lack of proactive planning was very evident in the area of intention for inclusion. Very few respondents identified intention toward proactive planning for accommodations or universal design, while the majority expressed the intent to continue with the current approach of problem-solving as issues arise. This problem-solving approach may work for individual programs in the short term, but this study highlights the need for state programs to develop an organizational approach to disability inclusion to support programs to be more proactive.

\section{Implications for Other Youth Development Programs}

Program evaluation for organizational learning and decision making requires a relevant theory of change, thoughtful design, and reflective interpretation (Weiss, 1998). The findings from this study emphasize the importance of understanding the needs of staff in multiple roles regarding disability inclusion. The approach of this study-theory-informed, in-depth interviews with systematic coding - provided useful insights for future directions of this program. The same methods could be used by other youth development programs to gain greater insight into barriers and facilitators for disability inclusion or other targeted areas for change. 


\section{Limitations}

The authors recognize the potential limitations to this study. First, this qualitative study was conducted in one western state and results may not be applicable to other geographic populations. Second, the study was conducted within one specific national youth development program and may have limited generalizability to other programs. Third, this study used the theory of planned behavior (Ajzen, 1991) as a conceptual model, a model that focuses on individual behavior change. The authors recognize that other models, including organizational change models, could provide alternative findings and identify other constructs that influence disability inclusion.

\section{Conclusion}

This study is a useful first step in understanding the current status of disability inclusion in a typical 4-H program. Inclusion of youth with disabilities is desired by staff in multiple roles, but appears to be challenging to implement. Facilitators to inclusion include attitudes and subjective norms, while barriers relate to lack of knowledge and resources for accommodations. Better data and deeper understanding of what staff need to implement inclusion may lead to more proactive planning and organizational strategies in the future. More research in this area would help youth development programs better prepare their staff to meet the needs of the diverse youth who are interested in participating in their programs.

Disabilty inclusion is anticipated to continue to be a growing issue within 4-H and other publicly funded out-of-school programs. Section 504 of the Rehabilitation Act of 1973 and the Americans with Disabilities Act of 1990 are civil rights laws that prohibit discrimination against individuals with disabilities in all areas of public life. The United Nations Convention on the Rights of Persons with Disabilities considers "full and effective participation and inclusion in society" (Article 3) as a fundamental human right (United Nations, 2006). How individuals with disabilities are included in many forms of community participation is receiving greater attention. This study can serve as a resource to other youth development programs in identifying an approach to review their programs to better understand the needs of their staff and plan for greater disability inclusion. 


\section{Acknowledgements}

The authors would like to thank Lyla Houglum for her early contribution to this study and her valuable insight as a 4-H profesional during the editing process. We would also like to thank Vulnerable Populations Youth with Disabilities Working Group member Kerri Vanderbom for her review of this paper.

\section{References}

Americans With Disabilities Act of 1990, Pub. L. No. 101-336, 104 Stat. 328 (1990).

Ajzen, I. (1991). The theory of planned behavior. Organizational Behavior and Human Processes, 50, 179-211.

Anaby, D., Hand, C., Bradley, L., DiRezze, B., Forhan, M., DiGiacomo, A., \& Law, M. (2013). The effect of the environment on participation of children and youth with disabilities: A scoping review. Disability and Rehabilitation, 35(19), 1589-1598.

Apsler, R. (2009). After-school programs for adolescents: A review of evaluation research. Adolescence, 44, 1-19.

Arnold, M. E., \& Silliman, B. (2017). From theory to practice: A critical review of positive youth development program frameworks, Journal of Youth Development, 12(2), 1-20. doi: 10.595/jyd.2017.17

Boone, D. A., Boone, Jr., H. N., Reed, C., Woloshuk, J. M., \& Gartin, S. A. (2006). Attitudes of Extension professionals toward involvement of special needs youth in 4-H programs. Journal of Extension, 44(6), Article 6FEA4. Retrieved from https://www.joe.org/joe/2006december/a4.php

Braun, V., \& Clarke, V. (2006). Using thematic analysis in psychology. Qualitative Research in Psychology, 3(2), 77-101. doi: 10.1191/1478088706qp063oa

Daud, R., \& Carruthers, C. (2008). Outcome study of an after-school program for youth in a high-risk environment. Journal of Park \& Recreation Administration, 26(2), 95-114.

Deutsch, N. L., Blyth, D. A., Kelley, J., Tolan, P. H., \& Lerner, R. M. (2017). Let's talk after-school: The promises and challenges of positive youth development for after-school research, policy, and practice. In N. Deutsch (Ed.), After-school programs to promote positive youth development (pp. 45-68). Charlottesville, VA : Springer.

Durlak, J. A., Weissberg, R. P., \& Pachan, M. (2010). A meta-analysis of after-school programs that seek to promote personal and social skills in children and adolescents. American Journal of Community Psychology, 45, 294-309. doi: 10.1007/s10464-010-9300-6 
Disability Inclusion in 4-H

Fennick, E. \& Royal, J. (2003). Community inclusion for children and youth with developmental disabilities. Focus on Autism and Other Developmental Disabilities, 18(1), 20-27. doi: $10.1177 / 108835760301800104$

Foley, J. T., Bryan, R. R., \& McCubbin, J. A. (2008). Daily physical activity levels of elementary schoolaged children with and without mental retardation. Journal of Developmental and Physical Disabilities, 20(4), 365-378. doi: 10.1080/13668250802688314

Ingram, P. D. (1999). Attitudes of Extension professionals toward diversity education in 4-H programs. Journal of Extension, 37(1), Article: 1FEA3. Retrieved from https://www.joe.org/joe/1999february/a3.php

King, G., Petrenchiky, T., Law, M., \& Hurley, P. (2009). The enjoyment of formal and informal recreation and leisure activities: A compairison of school aged children with and without physical disabilities. International Journal of Disability Development and Education, 55(2), 109-130. doi: $10.1080 / 10349120902868558$

Kleinert, H., Miracle, S., \& Sheppard-Jones, K. (2007). Including students with moderate and severe intellectual disabilities in school extracurricular and community recreation activities: A statewide teacher survey. Intellectual and Developmental Disabilities, 45(1), 46-55. doi: 10.1352/19349556(2007)45[46:ISWMAS]2.0.CO;2

LaVergne, D. D. (2013). Diversity inclusion in 4-H youth programs: Examining the perceptions among West Virginia 4-H youth professionals. The Journal of Extension, 51(4), Article 4FEA1. Retrieved from https://joe.org/joe/2013august/a1.php

Light, R. J. (1990). By design planning research on higher education. Cambridge, MA: Harvard University Press.

Lindsay, S., \& McPherson, A.C. (2011). Experiences of social exclusion and bullying at school among children and youth with cerebral palsy. Journal of Disability and Rehabilitation, 34(2), 101-109. doi: $10.3109 / 09638288.2011 .587086$

Maxwell, J. A. (2013). Qualitative research design: an interactive approach (3 ${ }^{\text {rd }}$ ed.). Thousand Oaks, CA: Sage.

McBreen, D. (1994). What Cooperative Extension should know about the Americans with Disabilities Act. Journal of Extension, 32(4), Article 4FEA1. Retrieved from https://www.joe.org/joe/1994december/a1.php

Mouton, L., \& Bruce, J. (2013). Current practices for training staff to accommodate youth with special health care needs in the 4-H camp setting. Journal of Extension, 51(1), Article 1RIB4. Retrieved from https://www.joe.org/joe/2013february/rb4.php

National 4-H Council. (2016). 2016 Annual report of the National 4-H Council. Retrieved from https://4h.org/about/annual-report/ 
Disability Inclusion in 4-H

National Survey of Children's Health. (2016). Data query from the Child and Adolescent Health Measurement Initiative, Data Resource Center for Child and Adolescent Health website. Retrieved from http://childhealthdata.org/browse/survey/results?q=1820\& $r=1$

Nowell, L. S., Norris, J. M., White, D. E., \& Moules, N. J. (2017). Thematic analysis: Striving to meet the trustworthiness criteria. International Journal of Qualitative Methods, 16(1), doi: $10.1177 / 1609406917733847$

Peterson, R. L., Grenwelge, C., Benz, M. R., Zhang, D., Resch, J. A., Mireles, G., \& Mahadevan, L. (2012). Serving clientele with disabilities: An assessment of Texas FCS agents' needs for implementing inclusive programs. Journal of Extension, 50(6), Article 6FEA7. Retrieved from https://www.joe.org/joe/2012december/a7.php

Riggs, N. R., \& Greenberg, M. T. (2004). After-school youth development programs: A developmentalecological model of current research. Clinical Child and Family Psychology Review, 73), 177-190.

Rimmer, J. H., Rowland, J. L., \& Yamaki, K. (2007). Obesity and secondary conditions in adolescents with disabilities: Addressing the needs of an underserved population. Journal of Adolescent Health, 41(3), 224-229. doi: 10.1016/j.jadohealth.2007.05.005

Rojewski, J. W., Lee I. H., \& Gregg, N. (2015). Causal effects of inclusion on postsecondary education outcomes of individuals with high-incidence disabilities. Journal of Disabilty Policy Studies, 25(4), 210-219. doi: $10.1177 / 1044207313505648$

Stumpf, M., Henderson, K., Luken, K., Bialeschki, D., \& Casey II, M. (2002). 4-H programs with a focus on including youth with disabilities. Journal of Extension, 4O(2), Article 2FEA4. Retrieved from https://joe.org/joe/2002april/a4.php

Stumpf-Downing, M., Henderson, K., Luken, K., \& Bialeschki, D. (2004). Creating inclusive 4-H environments for people with disabilities. Journal of Extension, 42(4), Article 4FEA1 Retrieved from https://www.joe.org/joe/2004august/a1.php

Taylor, J., \& Yun, J. (2012). Factors influencing staff inclusion of youth with disabilities in after-school programs. Therapeutic Recreation Journal, 46(4), 301-312.

Taylor-Winney, J., Xue, C., McNab, E, \& Krahn, G. (2017). Inclusion of youth with disabilities in 4-H: A scoping literature review. Manuscript submitted for publication.

Trost, S. G., Rosenkranz, R. R., \& Dzewaltowski, D. (2008). Physical activity levels among children attending after-school programs. Medicine \& Science in Sports \& Exercise, 40(4), 622-629. doi: 10.1249/MSS.0b013e318161eaa5

United Nations. (2006). Convention on the rights of persons with disabilities: Article 3 - General principles. Retrieved from https://www.un.org/development/desa/disabilities/convention-on-therights-of-persons-with-disabilities/article-3-general-principles.html

U.S. Department of Agriculture, National Institute of Food and Agriculture. (n.d.). Vulnerable Populations. Retrieved from https://nifa.usda.gov/program/vulnerable-populations 
Journal of Youth Development | http://jyd.pitt.edu/ | Vol. 13 Issue 3 DOI 10.5195/jyd.2018.604

Disability Inclusion in 4-H

Watts, C. E., Witt, P. A., \& King, T. (2008). Predictors of outcomes for after-school program participants. Journal of Park \& Recreation Administration, 26(2), 134-145.

Weiss, R. S. (1994). Learning from strangers: The art and method of qualitative interview studies. New York, N.Y: Free Press.

Weiss, C. H. (1998). Evaluation: Methods for studying programs and policies ( $2^{\text {nd }}$ ed). Upper Saddle River, NJ: Prentice Hall. 